\title{
Towards a National Graduate Destinations Survey in Kenya: an Exploratory Study of Three Universities
}

Tristan McCowan (UCL Institute of Education, London), Ibrahim Oanda (CODESRIA, Dakar) and Moses Oketch (UCL Institute of Education, London)

Author version

Published in Higher Education Policy, 2017.

DOI: $10.1057 / \mathrm{s} 41307-017-0044-x$

\begin{abstract}
While concerns about graduate unemployment and the work-readiness of graduates in SubSaharan Africa abound, there is a severe lack of institutional data and academic research on graduate destinations on which to base policy changes. This article presents findings from an exploratory study of three major higher education institutions in Kenya. An online survey was conducted of undergraduate students graduating between 6 and 12 months prior to the study, aiming to determine, first, what employment activities they were engaged in, and second, what associations there might be between those activities, the graduates' background characteristics, and their experiences at university. Findings suggest that proportions of absolute unemployment are lower than expected, but that many graduates are transiting between provisional or part-time employment and internships, and have not yet obtained the graduate level jobs aspired to. Finally, implications are drawn out for potential national-level graduate destination surveys in Kenya and elsewhere in Sub-Saharan Africa.
\end{abstract}

\section{Keywords}

African higher education; employability; graduate destinations survey; graduate employment; Kenyan universities

\section{Introduction}

There are worldwide concerns about the employment destinations of university graduates. In part, this is due to the reality of graduate unemployment in a context of rapidly increasing enrolments and stagnation of job opportunities. Connected with this trend is that of 'underemployment', in which graduates are obliged to work in non-graduate jobs, or in forms of work that do not utilise the skills and knowledge gained through their degrees. Another reason for interest in graduate destinations stems from a desire that public sector resources invested in the higher education (HE) sector achieve the aims of producing graduates who will 
contribute to economic and social development. The progressive marketisation of HE systems has provided further impetus: given intense competition to attract students, institutions have an interest in publicising the successes of their graduates; prospective students have an interest in determining what their likely job prospects will be; and governments have an interest in ensuring reliable information for 'consumers'. There is also the alleged mismatch between the graduate characteristics with respect to demand in the labour market and the knowledge, skills and attributes graduates possess - the issue of employability.

Africa is no exception to these global trends. A number of countries across the region are facing significant problems of graduate unemployment and underemployment (African Development Bank/UNDP 2012; Association of African Universities 2013), with up to $50 \%$ of university graduates not expected to get jobs in the formal economy after graduation (African Centre for Economic Transformation 2014). The white-collar work that was practically guaranteed for university graduates in the post-independence years is now far from universal, and young people increasingly have no option but to enter self-employment. Given this backdrop, and with the growth of private higher education and the introduction of fees in public institutions, students are increasingly attentive to their employment prospects. Accompanying these concerns are widespread perceptions of declining standards in universities, and a crisis of quality arising from spiralling enrolments and strained infrastructure, leading to the production of so-called 'half-baked' graduates who allegedly do not possess the knowledge, attributes and skills expected from higher education and required by prospective employers (Inter-University Council for East Africa/East Africa Business Council 2014).

Nevertheless, despite constant media reports and consensus amongst key stakeholder groups about the severity of the problem, evidence on graduate employment in Sub-Saharan Africa is scarce. In some countries there are national figures available for unemployment rates, but it is not possible to disaggregate these into graduates and others. In countries in which graduate employment rates are determined, what constitutes 'employment' is often ambiguous (Teal 2000). Furthermore, national and institutional figures for higher education enrolments, and the number of graduates emerging from universities, are unavailable or incomplete. These deficiencies in basic statistical information make research on the causes and implications of graduate employment prospects and experiences difficult. Moreover, few universities (or governments) have undertaken graduate destination surveys. This lack, coupled with the absence of comprehensive data sets providing background information on students and their experiences at university, means that institutions are neither accountable for their performance nor able to manage student expectations.

This study aims to address this lack of evidence in the context of Kenya. It forms part of a larger research project - Universities, Employability and Inclusive Development - running from 2013-2016, which aimed to understand the role of universities in promoting graduate employability in four countries: Ghana, Kenya, Nigeria and South Africa. This article reports on a sub-component of that larger project, a pilot study carried out in 2015 with three universities in Kenya, surveying recent graduates to gather information on their employment status, their perceptions of their current work, the influence of their studies on their work, and their future plans. The study aimed to address two questions: first, what employment activities are graduates engaged in 6-12 months after leaving university; and second, what 
associations are there between those activities and the background characteristics of the students, as well as their experiences at university?

The overall purpose of this study was to generate initial findings about the employment destinations of graduates in Kenya, to inform institutional and national policies and practices; and in addition, to enhance methodological understanding of the potential and demands of graduate surveys in the Kenyan (and Sub-Saharan African) context, so as to enable the development of effective university and/or national level surveys in the future. In relation to the first of these aims, some caveats are necessary. As will be discussed further, while the sample provides broad coverage in relation to key background characteristics such as type of institution, gender, disciplinary area and mode of study, it was not possible to ensure that the students were randomly selected. Furthermore, the three institutions participating in the study are amongst the most highly regarded in the country, so in interpreting the data it is important to remember that employment outcomes for graduates of other institutions may be considerably worse. In addition, the information generated about graduates was limited to their principal occupations (on account of the need to keep the questionnaire relatively short) and did not capture the involvement of many individuals in a range of activities in both the formal and the informal sectors, or the full complexity of their reasons for being out of or delaying employment.

This article has as its backdrop human capital theory assumptions in which those with higher education are seen to earn a premium in the labour market, and can even move to new careers as a response to bottlenecks in the labour market (McMahon and Oketch, 2010). Human capital may directly influence productivity by determining the capacity of nations to innovate and develop new technologies suited to domestic production (Romer, 1990). Consequently to expand participation rates in higher education in this context can be important because education is a key factor in the labour market, and in productivity nationally. Nevertheless, a number of theorists (e.g. Allais 2015; Marginson 2015; Robertson 2016) are critical of this perspective, on account of the lack of acknowledgement of factors other than productivity in explaining earnings, of the complexity of motivations for studying in higher education, and of the role of education systems in exacerbating initial inequalities. This article underscores the complexity of human capital theory in contexts such as Kenya where participation rates in higher education and the labour market may not relate in a linear way.

In spite of the methodological caveats, the study can provide some much-needed evidence to support higher education policy making in Kenya, and potentially for other countries in Sub-Saharan Africa. The survey provides some analysis of the link between employment and activities undertaken previously at university (e.g. careers guidance and work placements), and disaggregation of results by gender, institution and mode of study, so as to develop some initial insights into the factors influencing outcomes. A survey of final year graduate students carried out for the broader project (McCowan et al. 2015) showed that family networks are perceived to be a key facilitator of subsequent employment, helping to reproduce socioeconomic inequalities. Graduate destination survey evidence can provide pointers as to the extent to which interventions made in universities can help equalise chances for students. 
The article will start by providing background information on graduate destinations surveys in Sub-Saharan Africa and the context of the Kenyan higher education system, before presenting the research design of this study, followed by an analysis of the findings and their implications.

\section{Graduate destination surveys in Sub-Saharan Africa}

There is extensive literature and lively debate on the relationship between university graduates and labour markets, particularly in the context of the rising costs of providing university education and the introduction of fees in many countries (Pillay 2011, Ozor et al 2016). Furthermore, there are intense debates on the market alignment of public and private sectors, and about the cost-effectiveness of university education in terms of who should pay, who receives the benefits, and how much should be invested (McMahon and Oketch, 2013; Oketch, 2016). In this context, information on the employment status of university graduates is crucial. However, there is a serious lack of research on graduate destinations in the SubSaharan Africa region, with no destination surveys with complete national coverage, although there is evidence of increasing interest in this area from higher education institutions and regulatory bodies.

South Africa represents something of an exception in this regard. The Human Sciences Research Council carried out a graduate destinations survey of the 2003 graduating cohort from seven public universities (Letseka et al. 2010). In addition, the University of Cape Town's Development Policy Research Unit (2006) carried out an analysis of labour force survey data from 1995 and 2005. These surveys showed a large disparity in estimates of unemployment rate $-32 \%$ in the former as opposed to $10 \%$ in the latter - explained by the inclusion of cohorts in the latter study who had had a longer period to enter the labour market (CHEC 2013). A later study by Van der Berg and van Broekhuizen (2012) found that the problem of unemployment was largely confined to diploma holders, with the unemployment rates for graduates of Bachelor's courses or higher only $5 \%$. The country also has a prime example at the provincial level, the 'Graduate destination survey of the 2010 cohort of graduates from Western Cape universities' (CHEC 2013), carried out by the Cape Higher Education Consortium (CHEC). The survey targeted graduates from all four Western Cape universities across all qualification levels and academic fields - and was conducted two years after graduation in 2012. The report provides a range of insights into the destinations of students, and the associations between these destinations and various background characteristics, as well as characteristics of graduates' university study and prior schooling. The South African Graduate Employers Association (SAGEA) ${ }^{1}$ also produces annual surveys of employers and of the graduates they have recruited.

There are a limited number of studies from other African countries. Mugabushaka et al.'s (2003) study compared surveys from six Sub-Saharan African countries (Ghana, Kenya, Malawi, Nigeria, Tanzania and Uganda), tracing graduates from selected universities in each. The surveys in question were carried out in 1996-1997, and covered graduates who had left university in the 1980s and early 1990s. Amongst these graduates, there was shown to be only a $5 \%$ employment rate (explained by the long time they had been in the labour market),

\footnotetext{
${ }^{1}$ Formerly the South African Graduate Recruiters Association (SAGRA)
} 
although this figure rose to $10 \%$ for those who had graduated between 1993-1996. More recently in 2013, in Uganda, the National Council for Higher Education (UNCHE) undertook a tracer study of those who had graduated in 2005 (a total of 1,248) from five universities and four colleges), achieving a response rate of $65.9 \%$. Of note from this survey was that while $71.4 \%$ of diploma holders had found their higher education training very relevant to the skills required by their employers, only $49.5 \%$ of degree holders had. Other large scale national surveys have been undertaken in Ghana in 2010 (of agricultural graduates), while in Namibia, the National Council for Higher Education carried out a tracer study of 1999-2008 graduates in 2011.

In East Africa, a recent initiative by the Inter-University Council of East Africa [IUCEA] and the East African Business Council (2014) set out to identify and document 'Regional higher education qualifications gaps'. The study pointed to the lack of hard data as a serious obstacle to tracing higher education to employment pathways, as well as employers', students' and institutions' different understandings of the graduation to work transition. For example, while less than a third of young people and employers in the survey believed that new graduates were adequately prepared for the labour market, the higher education institutions surveyed largely believed that new graduates were ready for work.

In addition to these initiatives, there are some international partnerships aiming to encourage the generation of evidence on graduate destinations. For example, the IUCEA is coordinating an initiative to train middle and high level university managers on methodologies for conducting graduate tracer studies. The training programme is being offered by the Centre for Higher Education Development and Quality Enhancement (CHEDQE) at the University of Duisburg-Essen (UDE) in Germany, in cooperation with the Commission for University Education (CUE), Kenya. Another initiative is UNITRACE (University Graduates Tracer Study Course) - funded by the German Academic Exchange Service (DAAD) and led by the International Centre for Higher Education Research at the University of Kassell. Since 2010, this initiative has worked with universities in Kenya (Moi and Kenyatta), Ethiopia and a range of other countries, providing a series of workshops on the conducting, analysis and dissemination of tracer studies.

\section{The Kenyan context}

Kenya has a robust and expanding higher education sector, the largest within the East African region in terms of the number of institutions and student enrolments. With the passing of a new National Constitution in 2010 and a new higher education governance framework (The Universities Act 2012), the country embarked on rapid expansion of higher education to meet the demand. Higher education expansion is aligned with the country's development blueprint, Vision 2030, which aspires to transform Kenya by 2030into a prosperous and internationally competitive knowledge economy. The university sector is tasked with contributing to the attainment of this vision by delivering a wide range of learning and training opportunities to meet the varied needs of individuals and employers. Between 2010 and 2015 , the number of public universities increased from 12 to 23, while student enrolment in both public and private universities grew to 512,924 in the 2015/2016 academic year from 443,783 in 2014/15 academic year (Republic of Kenya 2016). 
Higher education expansion presents a significant challenge (Blom et al 2016). With low government capitation to fund the expansion, both public and private universities have had to rely on private household incomes, even though this is thought to have had an adverse impact on quality (Munene 2015; 2016). Public institutions have done this through the emergence of the 'parallel' stream, through which large numbers of fee-paying students are admitted alongside the government-sponsored ones entering through academic merit - often without corresponding expansion of infrastructure and staffing levels (Oanda \& Jowi 2012; Wangenge-Ouma 2007). Furthermore, the rapid expansion of higher education access has not been accompanied by a corresponding increase in graduate level jobs. In fact, this tendency is far from new, with Hughes's (1987) study showing the gradual outstripping of demand for graduates by supply between the period of 1969-1983.

However, it is not only a question of lack of graduate level jobs, but also of the quality of the workforce. The World Bank's Enterprise Survey for Kenya in 2013 showed that $29 \%$ of the firms sampled indicated an 'inadequately educated workforce' as a major obstacle to business growth (World Bank 2013), a finding corroborated by the IUCEA/East Africa Business Council study (2014), which showed that half of the graduates from the countries in the region lack work-readiness skills. The sustained expansion of the higher education sector is seen to have the potential to play an important role in the country's development, but only if students accrue skills relevant to the needs of the labour market and if graduate output is representative of a broad cross-section of Kenyan socioeconomic groups (Amimo 2012; Blom et al 2016). Despite the above concerns, initiatives focusing on quality-related transformations in the teaching and learning process are confined to a few institutions, and face considerable constraints (Brewis \& McCowan 2016).

Studies suggest that Kenya's unemployment problem is structural, where a willing workforce cannot find work or cannot meet the skill requirements for available vacancies (Kaminchia 2014). With respect to the employment prospects of university graduates, the situation is accentuated by two sets of factors. These are the low quality or non-existence of university career services and lack of labour market information flows among employers, the education system and graduates (USAID/MEDIA/fhi360, 2014).

In terms of the quality of jobs available for graduates, the Kenya labour market has over the last two decades been dominated by growth of the informal employment sector, a factor that continues to influence university graduate choices and destinations (Omollo 2012, Kaminchia 2014, Munga and Onsomu 2014). This has largely been due to the slow pace of economic growth that the country has faced since the 1990s when formal sector employment grew at a rate of $3 \%$ per year, while the informal sector grew at $26 \%$ per year, and in the subsequent decade, formal sector employment grew at $2 \%$ per year compared to $8 \%$ for the informal sector (Omollo 2012). At the same time, higher education institutions have expanded within the period, turning more and more graduates into a contracting formal labour market. Literature indicates that in 2014, only 1.3 million people worked in the modern formal sector, against over 12 million in the informal economy (Munga and Onsomu 2014), while the tertiary education system produces around 120,000 graduates per year. This continues to define the options tertiary education graduates have after graduation, with anecdotal evidence pointing to increased informalization of graduate labour markets and casualization of labour conditions (Omolo 2012). There are estimates that about $21 \%$ of those with university 
qualifications are engaged in vulnerable jobs in the informal sector (Munga and Onsomu 2014), with concerns that the expanding higher education sector has not reflected skill demands in the labour market.

The general lack of graduate destinations surveys in Africa also holds true for Kenya. At the national level, the government undertook a Workforce Survey in 2010/2011 that showed that there was an increasing tendency for graduate level positions to remain unfilled in both the public and private sectors due to skill mismatches (Republic of Kenya 2011). Studies have also been conducted by the private sector pointing out the gaps in skills training in the universities, the low quality of university careers services and the need for universities to improve tracking of graduates for labour market outcomes (IUCEA/East Africa Business Council, 2014, USAID/MEDA/FHI 360, 2014). Besides these studies and the training partnerships with Germany outlined above, and subsequent small-scale studies by Moi and Kenyatta universities, no comprehensive graduate tracer studies have been undertaken by institutions or national bodies.

\section{Research methods}

The aim of this study was to test the feasibility of mounting a national graduate destination survey in Kenya by assessing a range of factors, including the survey distribution platform, the response rate, the cooperation of universities and the understanding of questions by respondents. Being a pilot study, a decision was made to include only a small number of universities that were willing to participate and had contact information for their recent graduates. While the choice of institutions was in part pragmatic, it was important to have a spread representing the main types of institutions in the country. Three institutions were chosen: a public university in the capital Nairobi, a regional public university, and a private university. It was hoped that this selection would also provide some insights into the impact of institutional type on graduate outcomes. The institutions will remain anonymous here, in part to guarantee the confidentiality of responses, but also to avoid unhelpful judgements of specific institutions resulting from the findings. The purpose of this study is to develop insights into the trajectories of students and the possibility of developing a larger graduate destinations survey, not to make a simplistic ranking of institutions. As will be discussed further in the conclusion, care is needed with reading off the quality of institutions directly from employment outcomes.

The questionnaire adopted was informed by that used in the annual "UK Destinations of Leavers from Higher Education" survey, which was considered a good model on account of its brevity and its focus on factual questions, given that the aim of this study was to obtain basic factual information on student destinations, rather than in-depth and fine-grained perceptions. There were, however, some significant differences from the UK survey: not all of the questions in the latter were included, the survey did not require the name of the respondent to be provided, some extra questions were included (for example type of secondary school attended), and some further distinctions were made, for example between regular paid work and internships. 
A total of 20 items were included, covering the background characteristics of respondents, job search strategies, current occupation, university experience and future plans. The questionnaire was trialled with eight recent graduates from different faculties of a public university in Nairobi, in the form of a focus group discussion. Among the issues raised were: anonymity (it was anticipated that respondents would be unwilling to share information on their name, telephone numbers or email address); reordering of questions to ensure a logical flow; replacing numerical rating with phrases; and adjustment of terminology.

The final version of the questionnaire - along with an explanation of the purpose of the study - was sent out in July 2015, followed by a series of reminders to increase the number of responses. The survey was aimed only at those students who had graduated between 6 and 12 months before the issuing of the questionnaire. Only those completing undergraduate degrees were included, so as to ensure a clear focus for the study, in light of the distinctive factors at play in the employment of those with postgraduate qualifications. The universities only had contact details for a proportion of the graduates, and the survey was sent to all of these. The final group (referred to here as the sample) was comprised of those who responded to that invitation. A total of 3500 graduates were contacted via email and of these, 569 completed the online questionnaire (a response rate of $16.2 \%$ ). The regional public university provided contact details for few graduates, but amongst these few a high response rate was obtained.

Table 1

\begin{tabular}{|l|l|l|}
\hline UNIVERSITY & SENT & RESPONSES \\
\hline $\begin{array}{l}\text { Metropolitan public } \\
\text { University }\end{array}$ & 1290 & 228 \\
\hline Private University & 2082 & 259 \\
\hline Regional public university & 135 & 50 \\
\hline & TOTAL & $\mathbf{5 6 9}$ \\
\hline
\end{tabular}

The final response rate of $16.2 \%$ is broadly comparable to other surveys of this type. The CHEC study in the Western Cape obtained a higher proportion (22.5\%) through making additional telephone calls to those graduates who had not responded to the online questionnaire, a strategy that was not possible in this case on account of resource constraints. The responses to the questionnaire were collated on SurveyMonkey, and analysed using Microsoft Excel. The analysis involved simple descriptive statistics, assessing the overall distribution of responses for each question, and cross-tabulating in order to understand the distribution of responses across key background factors (institution, gender and mode of study). Some 59 respondents who had graduated prior to this period or had completed postgraduate qualifications were removed from the sample, leaving a total of 510 for inclusion in the analysis ${ }^{2}$.

\footnotetext{
${ }^{2}$ Some items were left unanswered by some respondents, hence responses do not total 510 in all cases.
} 
The distribution of the sample according to gender, and comparison with the enrolment figures for each institution as a whole, can be seen in Table 2:

\section{Table 2}

\begin{tabular}{|l|l|l|}
\hline & Sample \% female & Total \% female \\
\hline $\begin{array}{l}\text { Metropolitan } \\
\text { public university }\end{array}$ & $53 \%$ & $39 \%$ \\
\hline $\begin{array}{l}\text { Private university } \\
\text { Regional public }\end{array}$ & $52 \%$ & $(47 \%)^{3}$ \\
\hline university & $52 \%$ & $48 \%$ \\
\hline Total & $51 \%$ \\
\hline
\end{tabular}

It is clear that there is a substantial overrepresentation of females in the sample, both in terms of the overall sample (the overall proportion of females enrolled in higher education is $41 \%$ in Kenya [Republic of Kenya 2016]), and for each of the participating institutions. The percentage of female students in public universities is lower, averaging $41 \%$ compared to $47 \%$ in private universities for the last three academic years (Republic of Kenya 2016).

In Kenya, national secondary schools and high cost private secondary schools are the most prestigious. National secondary schools usually dominate the top 100 in the Kenya Certificate of Secondary Education (KSCE) examination results and their graduates take up the lion's share of university admissions through the Kenya Universities and Colleges Central Placement Service (KUCCPS). They also dominate highly sought-after courses such as law, information and communication technology, architecture, actuarial sciences, engineering and medicine. Only a small proportion (7.9\%) of the sample had studied in these institutions, with the vast majority coming from less exclusive provincial (55.7\%) and district (24.9\%) schools, indicating that the sample is not excessively skewed towards elite groups. Of the sample, $11.5 \%$ had studied in private secondary schools, compared to a national figure of $13 \%$ in this type of school (Republic of Kenya 2016).

The majority of students surveyed were in parallel programmes (either full or part-time) - a distinction that is relevant for the public universities, rather than the private one. Mode of studies of students is a relevant factor, partly because these groups have different background characteristics, but also because it entails a different relationship with the workplace. Typically, part-time students are already in employment and continue working during their studies. In terms of discipline studied, there was a broad spread of respondents from business studies, health science, arts and humanities, IT, economics and social sciences.

\footnotetext{
${ }^{3}$ The figure for the proportion of females across the whole of this institution is not available; hence, the figure for the whole of the private sector is used as a proxy.
} 
The sample, therefore, broadly corresponds to what might be expected in the total population of students at these universities, although with a skew towards females. There is little reason to believe, therefore, that the employment outcomes for this group would be significantly different from the total population of graduates on the basis of their background characteristics. Nevertheless, in an optional survey of this type, in which approximately one in six people respond, there may be some self-selection bias. As argued by Mugabushaka et al. (2003), 'successful' graduates may be more likely to participate than those who have not found employment. Furthermore, the graduates who responded to the survey may have particular characteristics, attitudes or tendencies of a more subtle nature than the categories discussed above: for example, they may have a better internet connection, be more assiduous in responding to communications, have a greater sense of social responsibility, or have more leisure time. These factors may be associated with higher or lower rates of employment, different types of employment and so forth. Given the complexities of these factors, it is not possible to predict exactly what influence they may have, but awareness must be retained of the tentativeness of these findings.

\section{Survey findings}

This section will outline the principal results of the survey, focusing on two main areas: first, current employment status, including form of employment, salary level and graduates' future intentions; and second, links with their university studies, involving their perceptions of the relevance of knowledge acquired during their studies and career enhancing activities. For each of these areas the overall results will be discussed, as well as disaggregating by subgroup where possible.

\section{a) Current employment status}

The headline finding of this pilot study is that the rate of absolute unemployment in the sample, while substantial, is lower than might be expected at $14 \%$. Figure 1 shows the current employment status of respondents: 


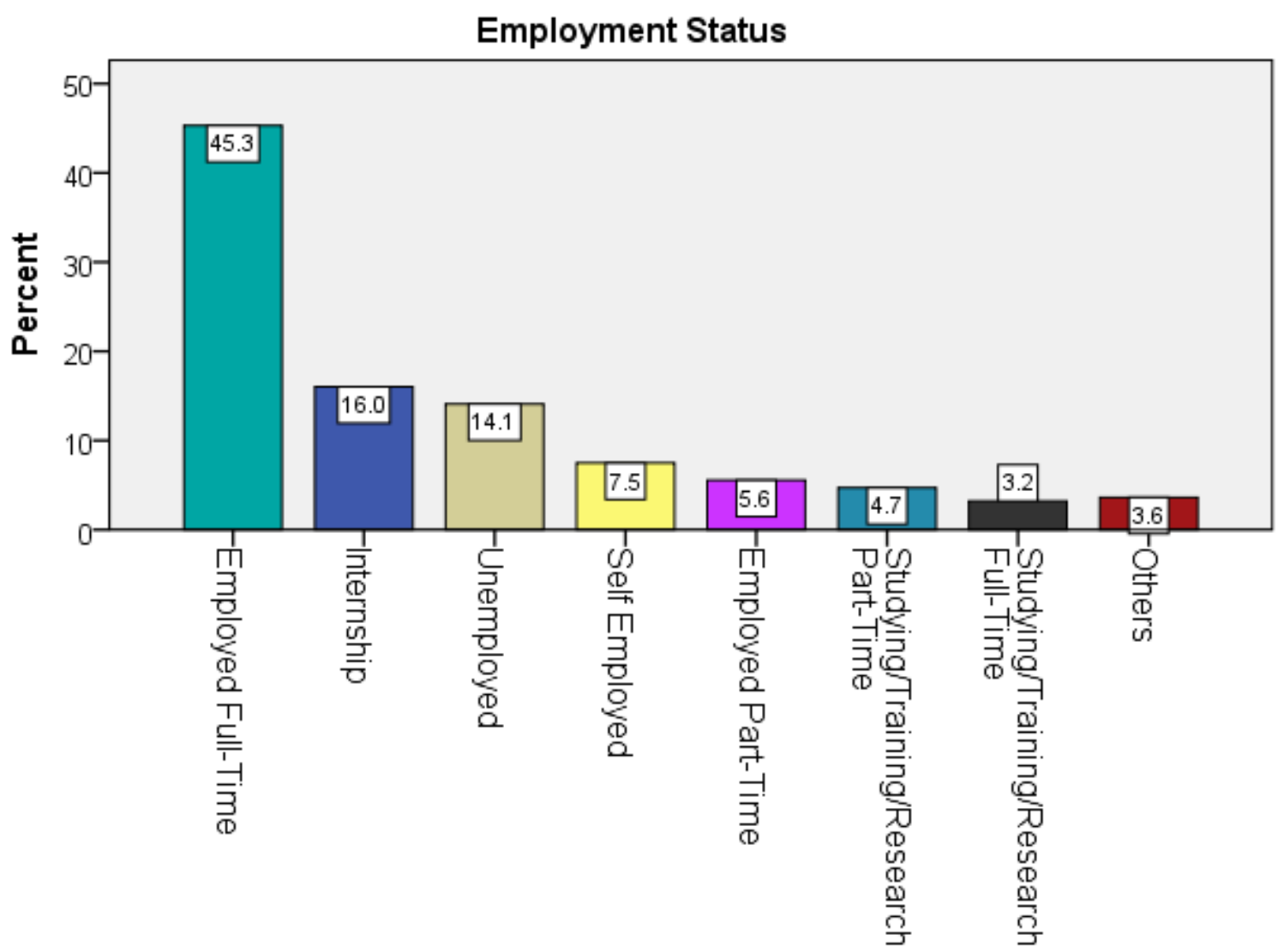

Employment Status

Missing: 42

These figures appear to challenge commonly held assumptions about high levels of unemployment - and claims that it takes a graduate an average of five years to obtain a job (Omolo 2013). What characterises this distribution overall is not absolute unemployment, but a diverse range of activities building up to full employment. Less than half of the respondents were working full-time, but almost an equal proportion were spread across other activities such as part-time work, internships, self-employment and further study. It is likely that the piecemeal nature of many graduates' occupations would be revealed to an even greater extent had respondents been asked to report on their subsidiary occupations. In addition, more than half of the respondents had been in employment before entering their degree course, with some retaining or returning to their previous jobs. For those who have not had this prior experience, finding a job is more difficult, as shown below.

One surprising result was the relatively low proportion of graduates in self-employment particularly given the findings of a previous study that over $60 \%$ of final year students were intending to become self-employed (McCowan et al. 2015). It is possible that graduates are engaged in their own small businesses in addition to other forms of employment, but had not reported this in the survey question, or alternatively that self-employment rates may increase 
over the years after graduation as time is needed to generate the necessary start-up capital and skills.

Disaggregation of the sample is revealing in terms of these employment outcomes. Full-time employment rates are similar amongst males and females, but the former are more likely to be unemployed and the latter more likely to be in internships.

\section{Figure 2}

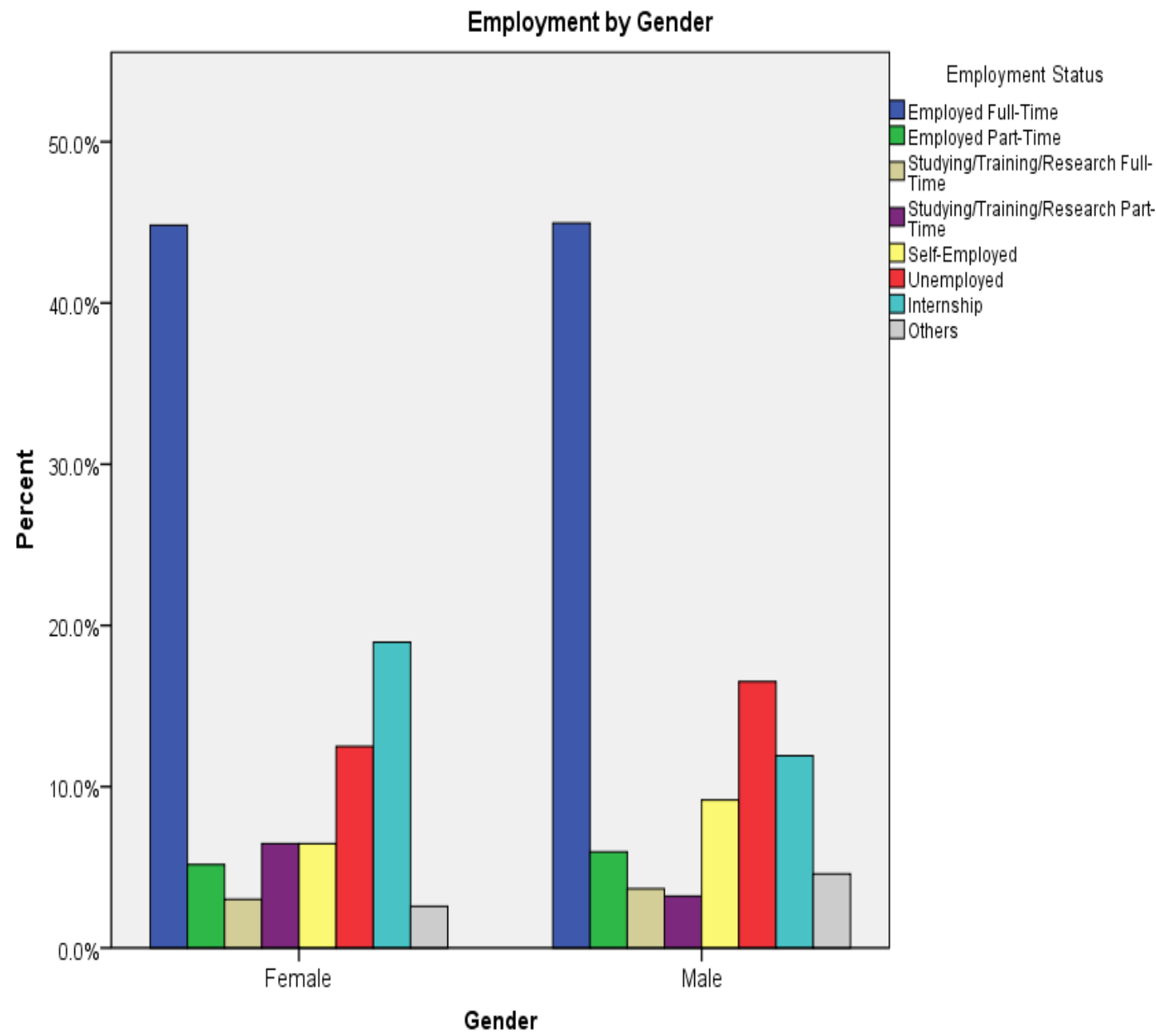

There is a significant difference between the three institutions, with the private university graduates having much higher levels of full employment (62.7\%) than either of the two public universities (metropolitan 27\%, regional 38.3\%), and lower levels of unemployment, parttime work and internships. However, much of this can be explained by the mode of study, with those who had been full-time students (much more common in the public universities) more likely to be unemployed and less likely to have found full-time employment - since they are not continuing with existing jobs as many as part-time students are. The full time parallel stream students at the public universities did not have better employment outcomes than the regular students ${ }^{4}$.

\footnotetext{
${ }^{4}$ The distinction between parallel and regular students is only relevant for public universities. However, the option parallel/full-time in this case includes a number of students from the private university, who might also
} 


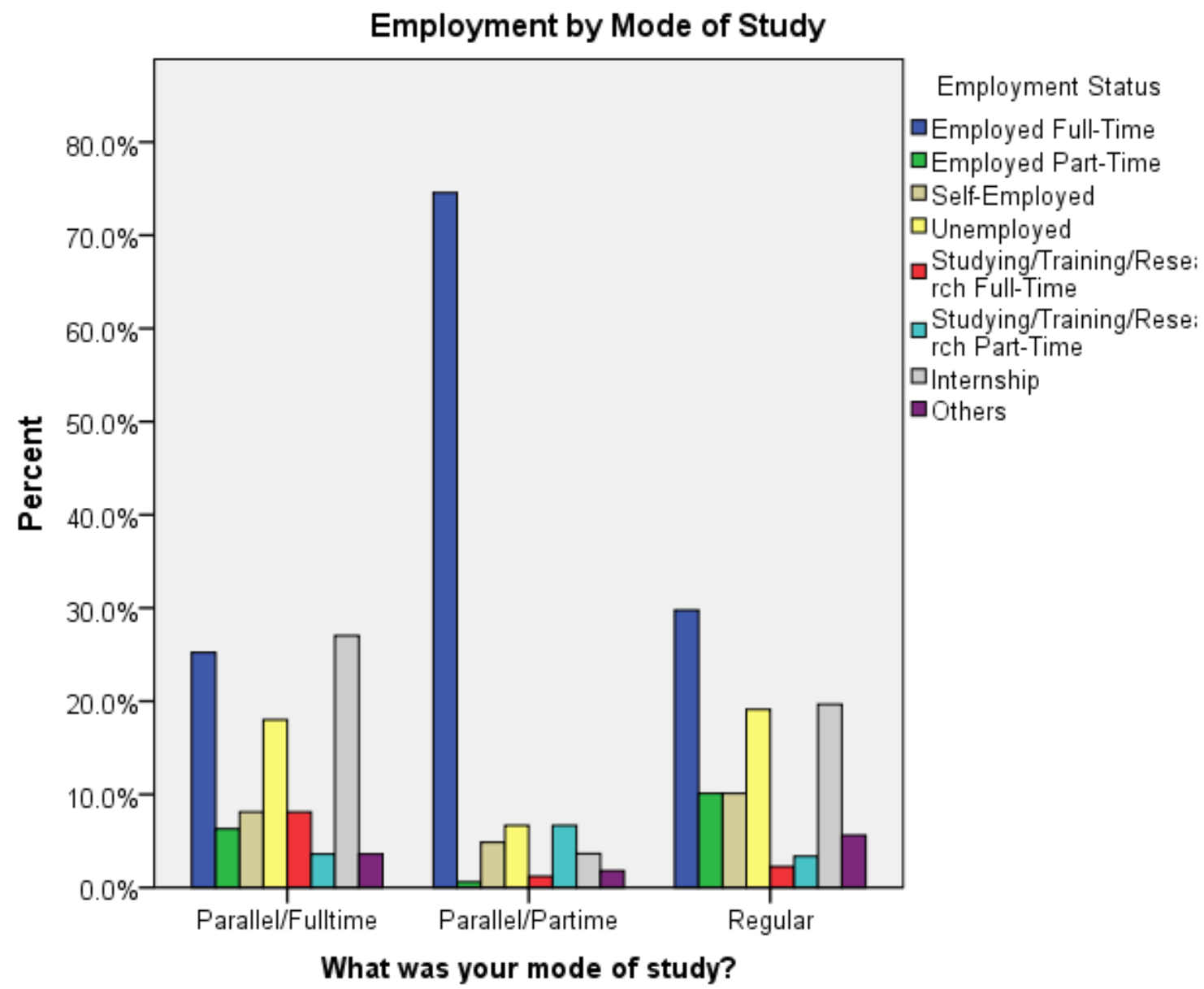

The most dramatic association, however, was that between employment status and whether students had previously worked: $60 \%$ of those who had worked before their studies were in full time employment, compared to only $30 \%$ of those who had not, while a higher proportion of the latter were in internships or part-time employment:

have been listed in the regular category. Most of those in the 'parallel/part-time' category are part-time students at the private university. 


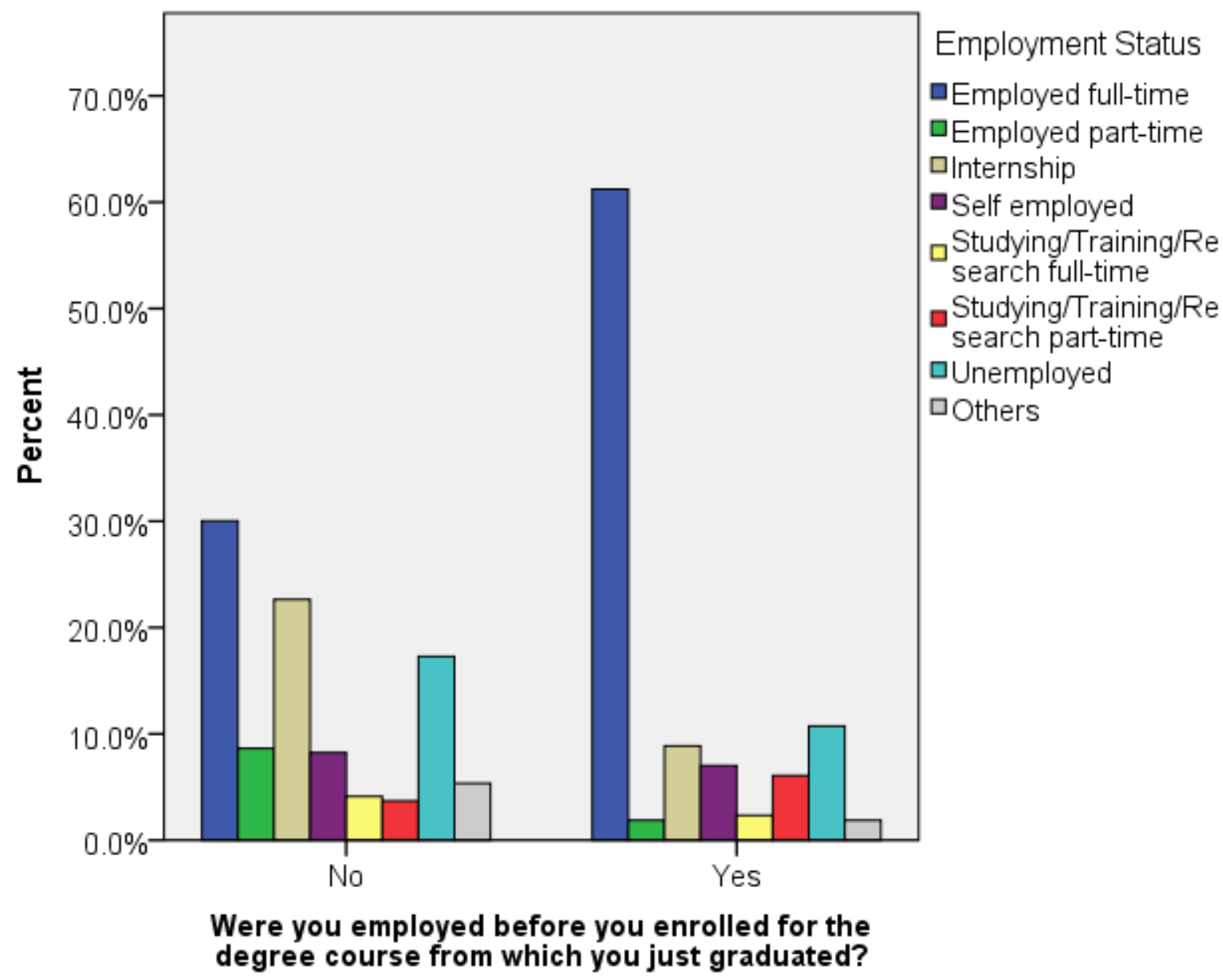

There are a range of indications that despite the low levels of open unemployment, recent graduates are not in an ideal situation as regards their occupation. From the responses provided in the survey, it can be seen that there is a wide variety of levels of responsibility and status, from doctors and managers to receptionists and sales assistants, but it is not always clear within the broad category whether the work undertaken is of 'graduate' level. The most common job categories were finance and accounting (14.2\%), administration and project management $(11.7 \%)$, healthcare $(10.4 \%)$, teaching $(6.9 \%)$, sales and marketing $(5.7 \%)$ and IT (4.1\%). Nevertheless, some insights into the level of work can be derived from the salary levels, which are relatively low, as can be seen on Figure 5 : 


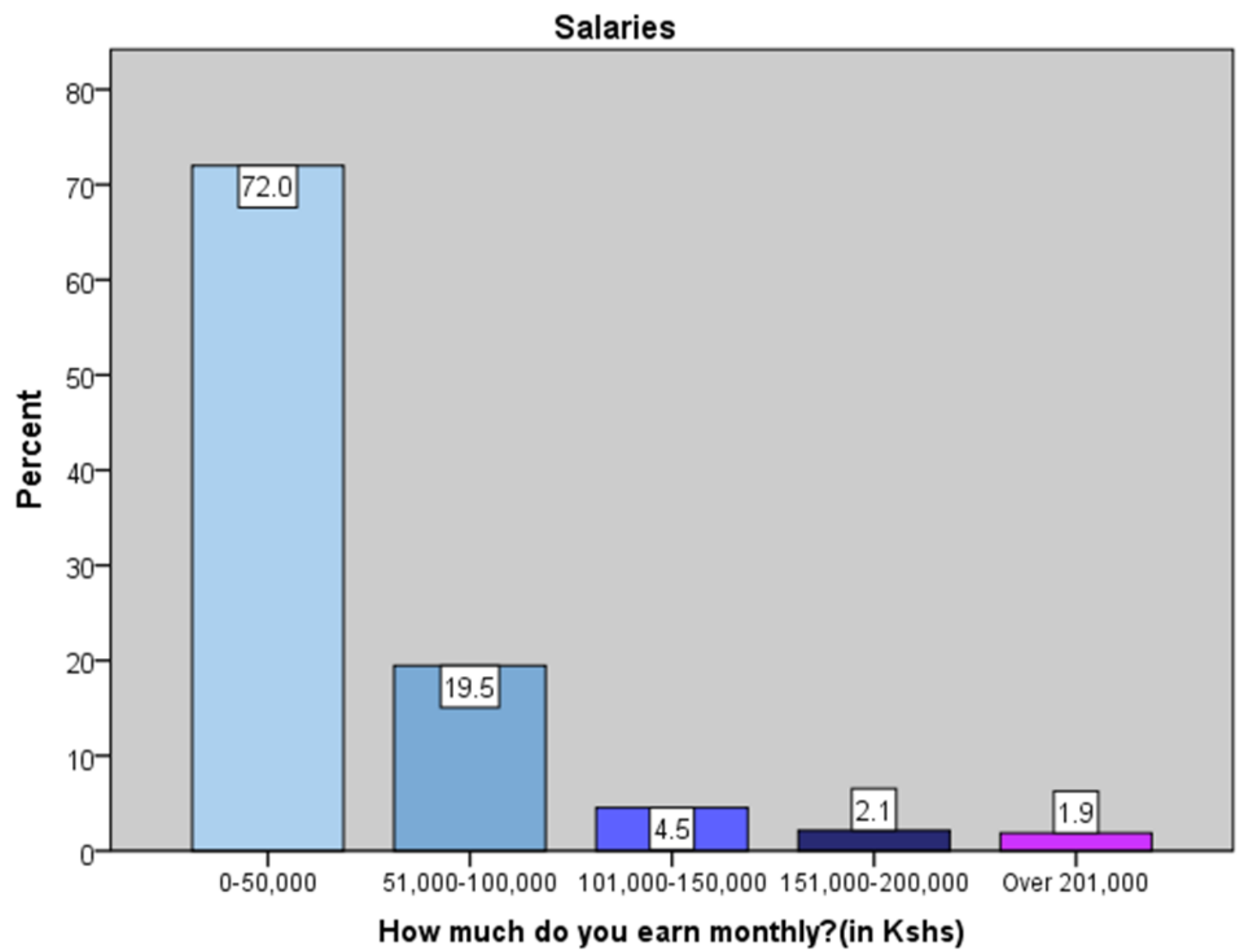

Missing: 135

In order to contextualise these levels, the starting salary of a graduate teacher in the public service is currently KSH 29,000 (approx. €260) per month and that of a doctor KSH 60,000 (approx. €535), showing that the vast majority of those employed are earning entry-level salaries (as might be expected) or possibly non-graduate level salaries.

Further cautionary notes are provided by the perceptions of graduates towards their current employment. Graduates were asked why they had taken on their current job, and responded with a diverse range of reasons, most common of which (36\%) was "To gain and broaden my experience in order to get the type of job I really want". However, the most striking evidence of the provisional nature of current work - or possibly dissatisfaction with that work - is shown by the result that only $17 \%$ of graduates are sure that they would like to continue in their current employment, with $65 \%$ stating that they would like to change their job, and $18 \%$ unsure.

Furthermore, over $90 \%$ of respondents intend to move on to further study, indicating that they feel the need to up-skill further in order to obtain the employment that they desire. Of course, this is an aspiration, and may not translate into reality, but it does send a clear signal, as well as reflecting the entrenched credentialism in the region. 
The evidence is strong that most recent graduates are indeed economically active, but are engaged in relatively low paid and provisional forms of work that they see as stepping-stones towards a 'real' career.

b) Influence of university studies

A further main area of findings relates to the link between current activities and the degree course studied at university. As regards the perceived link, results here are mixed: $45 \%$ of respondents saw their work as being strongly linked to their studies, with $36 \%$ seeing some connection ${ }^{5}$ and $19 \%$ seeing no connection at all. Similar findings were obtained in relation to the extent to which graduates were able to put to use the knowledge that they had gained at university: with $41 \%$ stating to a large extent, $48 \%$ somewhat $^{6}$ and $12 \%$ not at all. These figures compare unfavourably to the $70 \%$ of respondents in the Mugabushaka et al. (2003) study reporting high levels of utilisation of knowledge acquired.

Graduates were also asked to report on the concrete activities that they had undertaken at university to enhance their career opportunities. Provision of careers advice was seen to be patchy: in answer to the question of whether they had received any careers guidance from the universities, $41 \%$ of graduates answered yes, $26 \%$ a little and $32 \%$ no. While the majority of students therefore had received some advice, provision and take-up is far from comprehensive or universal. This reinforces the findings of a previous study on final year students that showed that only one in three students across the surveyed institutions had received any careers advice during their time at university (McCowan et al. 2015). The specific forms of career guidance received are outlined below:

\footnotetext{
${ }^{5}$ This includes the categories of 'a little bit' and 'here and there'.

${ }^{6}$ See previous footnote.
} 


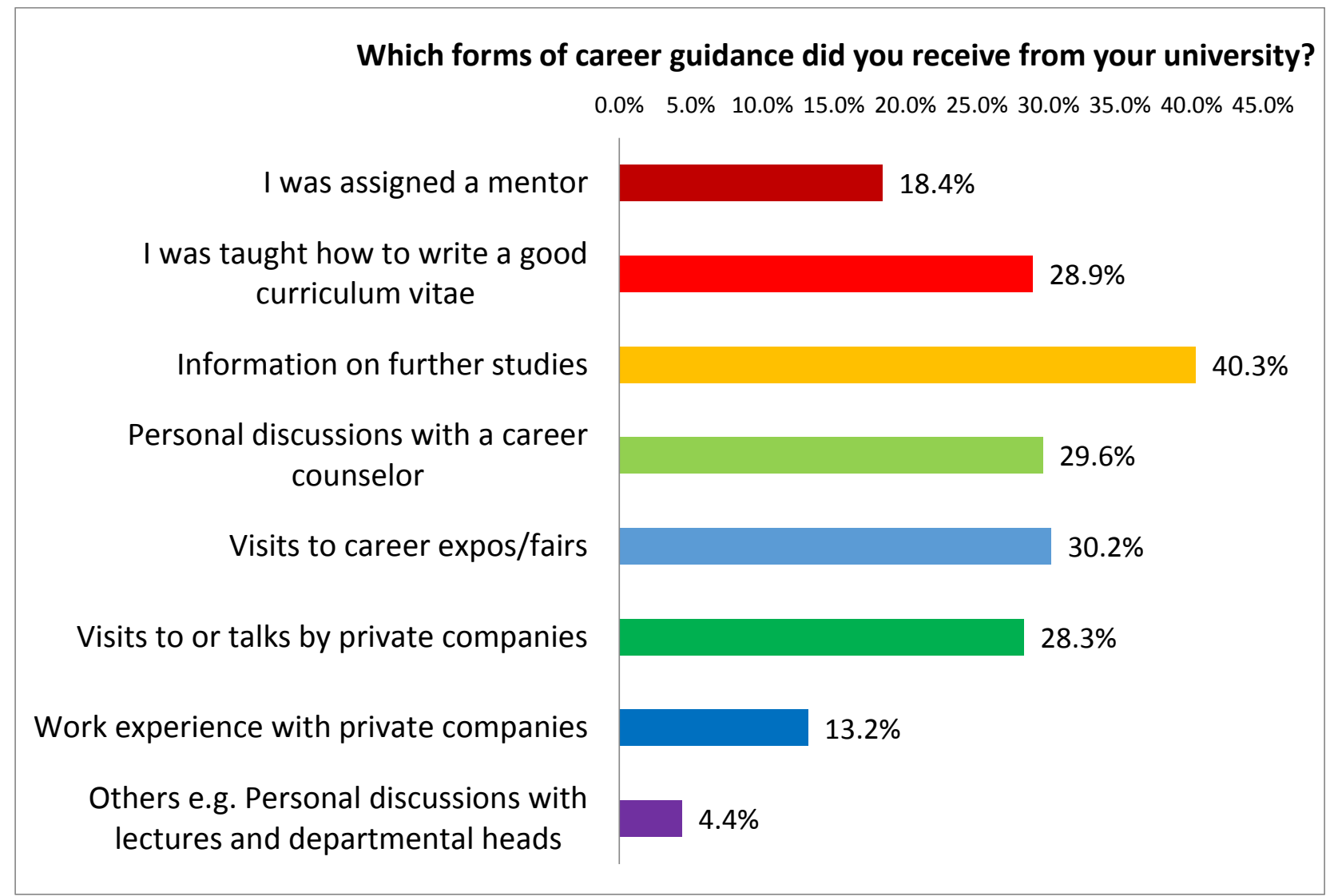

One positive aspect is the very high rates of work experience, with over $85 \%$ of respondents reporting that they had undertaken some form of placement during their studies. Other research (e.g. Mason et al. 2006; Wilton 2012) suggests (though not always conclusively) that these placements have a positive influence on subsequent employment opportunities. However, in this study, those graduates who had not undertaken internships/work experience during their degrees had slightly higher rates of full-time employment and lower rates of unemployment. A possible explanation for this unexpected result is that those parttime students with existing full-time jobs - and therefore higher rates of subsequent employment - had not needed to undertake work experience while at university.

\section{Implications of the study}

a) Implications of the findings for policy and practice

As outlined above, firm claims cannot be made from this pilot study about all university graduates in Kenya, or even all graduates from the institutions in question. There is a possibility that - due to self-selection bias - those responding to the survey had more positive employment outcomes than those who did not, although the relevant factors are complex and their influence on the findings hard to predict. Nevertheless, a well distributed sample of more than 500 graduates can provide some illuminating pointers. 
Overall, the results support the idea that the problem in Kenya is not one of absolute graduate unemployment, but of finding appropriate graduate level employment. The indications are that graduates are in a situation of fragmented careers - experiencing high levels of so-called job 'churn' - piecing together different opportunities, and combining them with further studies in order to achieve a permanent graduate level job. This contrasts strongly with the findings of Mugabushaka et al. (2003) of graduates in the 1980s and 1990s amongst whom there were very low levels of part-time work and self-employment. This situation is far from ideal: we are certainly a long way from the time in which graduates were virtually guaranteed a permanent graduate level post on leaving university. Yet neither is this the 'doom and gloom' scenario often painted in the media. Graduates are not spending years languishing in open unemployment, but are actively engaging in a range of pursuits to manoeuvre themselves into a better position to compete in the labour market.

In this regard, it is important to bear in mind the significant differences between 'regular' students, and those studying part-time - either in private universities or in the parallel stream at public universities. The latter students are likely to have been working before they joined the university, and as seen above, there is a dramatic difference in the proportion of those in full-time employment when those who had and had not worked before starting their degree are compared. Another point of relevance here is that students in the parallel stream also generally have greater freedom to pick a course that interests them. Regular students are allocated to courses on the basis of their Kenya Certificate of Secondary Education grades, so may not enter a course of their choice.

Only tentative implications can be drawn out of the data for the impact of particular aspects of university study on employment opportunities. It is not possible for this survey to provide evidence in relation to the level of knowledge and skills that graduates bring to the workplace, and thereby to contribute to the 'skills gap' debate. Nevertheless, the findings suggest that the preparation that students obtain within the universities could be significantly enhanced. Many graduates are working in areas that they do not perceive to link explicitly with their areas of study, and in an increasingly diversified labour market this trend is likely to continue. Universities should therefore pay more attention to the development of transferable skills, while not relinquishing the need to develop in-depth knowledge within a specific area. While the availability of work placements is a positive finding, careers services need to be enhanced in order to provide more students with appropriate advice and opportunities to develop their skills and networks. It must be recalled - both in relation to this element and the employment outcomes - that the three universities included here are amongst the best in the country, so we would expect the results to be more worrying across the whole of the system.

Finally, while the data gathered here did not explore the socio-economic background of the respondents in depth, issues of equity are critical in Kenyan higher education. Students from more privileged backgrounds have a significant advantage in accessing the best courses and the best jobs - with inequalities fuelled by the centrality of family networks in securing employment (McCowan et al. 2015) - thus presenting a challenge to some of the assumptions of human capital theory. In the sample assessed here, those studying at the private university had significantly better employment outcomes than graduates of either of the public universities. However, care must be taken in drawing any conclusions about the private sector as a whole, first, because the private institution participating in the study is well established 
and has a strong employability focus in its programmes, and second because most of the parttime graduates in the survey, who were already in employment before completing their degrees, were studying in the private institution.

b) Implications for the development of a national survey

The study also presents a range of implications for the development of larger scale graduate destinations surveys, in Kenya and elsewhere in Sub-Saharan Africa. First, the important insights generated even from this small sample show how worthwhile it is to engage in these forms of research. There are also promising signs in the level of response to initial emails, even without adopting other measures such as follow-up telephone calls. Even a small number of factual questions can generate much-needed evidence to support policy and practice in relation to preparation of graduates for their future lives.

As expected, a range of obstacles were also encountered. Incomplete alumni records made it hard for contact to be made with graduates: in the case of one university the records of email addresses were held only in handwritten form, leading to significant risk of error. Given the frequency with which email addresses and other contact details change, substantial efforts are needed to maintain up-to-date records. This factor is part of a much deeper challenge in Kenyan universities relating to the recording and availability of information. Not only are alumni contact details not always held, but it is hard even to obtain reliable enrolment information. This is due in part to a lack of administrative capacity in institutions, but in some cases also to commercial sensitivity, with some universities unwilling to divulge the exact numbers of fee-paying students. In these conditions it is extremely difficult to obtain reliable information, and to compare the results of destination surveys with the background characteristics of students.

Another challenge is staggered graduation times: institutions show considerable diversity in this respect, making such a survey hard to coordinate across the sector. Looking beyond Kenya, other challenges are presented by delayed entry into employment in certain countries. In Ghana and Nigeria, for example, students are obliged to do a year of national service after completing university, while in South Africa it is common to do an extra year of honours study after completing a basic degree. These factors make the timing of the survey crucial.

Another major factor that was not an obstacle in this particular study - though would certainly come into play when rolling out a national survey - is the potential for interference at institutional and national levels. One of the reasons that more tracer studies are not available is that institutions may be unwilling to make the results public, especially if they are not flattering! This is particularly true in an increasingly marketised context, given the need to recruit fee-paying students. At a national level, there may also be pressures to massage results on the basis of political agendas.

This exploratory study has generated some important lessons about how a national survey might be constructed and effectively conducted. In the first place, there are issues relating to the items on the survey: for example, the need for further indicators of socio-economic background, possibly along with other background characteristics - ethnic group, marital 
status and number of children, the need for finer-grained salary information in the lower bands, multiple forms of employment, and information on whether graduates are employed in the public or private sector. Considerable piloting of instruments is needed to make sure that key terms (e.g. 'unemployed') are interpreted appropriately. There are also issues relating to how to ensure the highest possible response rate: in this regard, ongoing contact with alumni from the moment they graduate is critical, along with potential incentives for students and their institutions to participate. Finally, given the sensitivities discussed above, considerable thought needs to be given to the question of institutional anonymity, the risks of 'naming and shaming' and potential interference in the results.

As discussed above, the CHEC study provides important pointers for subsequent graduate destinations surveys. For example, the use of follow-up telephone interviews can help address selection bias, as they can reach those who do not use email regularly (du Toit et al. 2014; du Toit 2016). However, the conditions for conducting these surveys in Kenya and many other countries in Sub-Saharan Africa are more challenging than in the Western Cape (South Africa), on account of incomplete student records and lack of administrative capacity, along with a range of other issues. Rolling out a graduate destination survey successfully across the country will depend on fundamental processes of capacity building in universities.

While this article has argued for the importance of conducting graduate destination surveys, some caveats are needed. For a start, caution is needed with assuming that the role of universities is exclusively to produce workers for the employment market: equal attention is needed to the civic, ethical and intellectual development of students, as well as ensuring that graduates contribute to the public good, rather than the solely the interests of their immediate employers (McCowan 2015). Second, there are dangers of using reductive gauges of employment outcomes (i.e. percentage of graduates in work after a particular period of time) to judge the quality of institutions - as is currently being debated in the UK in relation to the proposed Teaching Excellence Framework.

Nevertheless, there are still compelling reasons for conducting graduate destination surveys, as long as these caveats are borne in mind. The vibrant debate around questions of higher education and employability in Kenya, and the genuine concerns about graduate unemployment, underemployment and the quality of universities, have not been underpinned by adequate information and rigorous research. Basic evidence is urgently required on what graduates go on to do on completing their studies, so as to understand more fully how best to support them during their time at university and afterwards.

\section{Acknowledgements}

This study was carried out with funding from the British Council as part of the Universities, Employability and Inclusive Development research project (2013-2016). We are grateful to Zipporah Ongwenyi and Alex Ondieki for their assistance in data collection and analysis, and to Carole Rakodi and Denise Hawkes for their comments on earlier versions of the article. 


\section{References}

African Centre for economic Transformation, ACET, (2014). Growth with DEPTH; African Economic Transformation Report 2014, African Centre for Economic Transformation.

African Development Bank/UNDP (2012). African Economic Outlook 2012; Promoting Youth Employment. African Development Bank, Organization for Economic Co-operation and Development, United Nations Development Programme, United Nations Economic Commission for Africa.

Allais, S. (2015) Livelihoods and Skills. In T. McCowan and E. Unterhalter (eds) Education and International Development: an Introduction. London: Bloomsbury.

Amimo, C. (2012) Tailoring Higher Education in Kenya to the Demands of the Postindustrial Work Place. Baraton Interdisplinary Research Journal, 2(1) 52 - 58.

Association of African Universities (2013) "Transforming African Higher Education for Graduate Employability and Socio-Economic Development". Proceedings of the $13^{\text {th }}$ general Conference of AAU. Libreville, Gabon.

Blom, A., Raza, R., Kiamba, C., Bayusuf, H. and Adil,M. (2016) Expanding Tertiary Education for well paid Jobs, Competitiveness and Shared Prosperity in Kenya. Washington DC. The World Bank.

Brewis, E and McCowan, $T$ (2016) Enhancing teaching in African higher education: perspectives of quality assurance and academic development practitioners in Ghana, Kenya, Nigeria and South Africa. London: British Council.

Cape Higher Education Consortium (CHEC) (2013) Pathways from University to Work. Cape Town, South Africa: CHEC.

du Toit, J., Kraak, A., Favish, J. \& Fletcher, L. (2014) From study to work: methodological challenges of a graduate destination survey in the Western Cape, South Africa, Assessment \& Evaluation in Higher Education, 39:7, 853-864

du Toit, J. (2016) Can we augment web responses with telephonic responses to a graduate destination survey? Assessment \& Evaluation in Higher Education, 41:4, 560-574

Development Policy Research Unit (2006) Graduate unemployment in post-apartheid South Africa: nature and Possible Policy Responses. Research compiled for Standard Bank and Business Leadership South Africa. School of Economics, University of Cape Town.

Hughes, R. (1987) Revisiting the Fortunate Few: University Graduates in the Kenyan Labor Market. Comparative Education Review, 31 (4), 583-601. 
IUCEA/East African Business Council.(2014). "Regional Higher Education Qualification Gaps: Vol II. Situation Composite EAC Report". Kampala. IUCEA

Kaminchia, Sheila (2014) Unemployment in Kenya: Some economic factors affecting wage employment. African Review of Economics and Finance, 6 (1), 18-40

Letseka, M., Cosser, M., Brier, M., and Visser, M. (2010) Student Retention and Graduate Destination: Higher Education and Labour Market Access. Pretoria. Human Sciences Research Council.

Marginson, S. (2015) Rethinking education, work and 'employability'. Foundational problems of human capital theory. Keynote presentation at the Society for Research in Higher Education annual conference, Newport, $9^{\text {th }}$ December.

Mason, G., Williams, G., and Cranmer, S., (2006) Employability Skills Initiatives in Higher Education: What Effects do they have on graduate labour market outcomes? National Institute of Economic and Social Research.

McCowan, T. (2015) Should universities promote employability? Theory and Research in Education. 13 (3), 267-285.

McCowan, T., Ananga, E., Oanda, I., Sifuna, D., Ongwenyi, Z., Adedeji, S., Oyebade, S., Walker, M., Fongwa, S., and James, Z. (2015) Students in the Driving Seat: young people's voices on higher education in Africa, British Council, 17. Available online at: https://www.britishcouncil.org/sites/default/files/2.5 students-in-the-drivingseat_report_overview.pdf

McMahon, W.W. and Oketch, M (2010) Bachelor's and Short Degrees in the UK and US: New Social Rates of Return and Non-Market Effects on Development. LLAKES Research Paper 12.

McMahon, W.W. and Oketch, M. (2013). Education's effects on Individual Life Chances and Development: An Overview, British Journal of Educational Studies, Vol 61, No. 1, p. 79107.

Mugabushaka, A.-M., Teichler, U. and Schomburg, H. (2003) Failed or Self-Hindering Prophecies? Employment Experiences of African Graduates in the1990s. Journal of Higher Education in Africa. 1 (1), pp. 57-77

Munene, I. (2015) Profits and Pragmatism: The Commercial Lives of Market Universities in Kenya and Uganda. SAGE Open, October-December, 1-14

Munene, I. (2016) Kenya's universities are in the grip of a quality crisis. The Conversation, https://theconversation.com/kenyas-universities-are-in-the-grip-of-aqualitycrisis-54664 
Munga, B. and Onsomu E. (2014) The State of Youth Unemployment in Kenya. Available at https://www.brookings.edu/blog/africa-in-focus/2014/08/21/state-of-youthunemployment-in-Kenya/. Accessed 23/1/17.

Oanda, I. O. and Jowi, J. (2012) University Expansion and Challenge to Social Development in Kenya; Dilemmas and Pitfalls. Journal of Higher Education in Africa, 10/1: 49-71.

Oketch, M. (2016). Financing Higher Education in Sub-Saharan Africa: Some Reflections and Implications for Sustainable Development. Higher Education, 72, 525-539.

Omolo, J. (2012). 'Youth employment in Kenya: Analysis of labour market and policy interventions', Friedrich-Ebert-Stiftung Occasional Papers No. 1.

Omolo, J. (2013) Employment Challenges in Kenya, African Journal of Economic Review, 1 (1), 18-32.

Otieno, D. (2016) Choice of private schools paying off, admissions data shows', Daily Nation, Nation Newsplex, http://www.nation.co.ke/newsplex/Form-one-selection/2718262/3088530/-/52nykpz/-/index.html

Ozor, N., Acheampong E., Lamptey A. and Njagi, D. (2016). "Improving the Relevance of University Training to Labour Market Demands in Africa". African Technology Policy Studies Network Technology Brief No 47. Nairobi. African Technology Policy Studies Network/ Association of African Universities

Pillay, P. (2011). Higher Education and Economic Development: Literature Review. Cape Town: Centre for Higher Education Transformation.

Republic of Kenya (2016) Economic Survey. Nairobi: Government Printer

Republic of Kenya (2014) Kenya Country Report for the 2014 Ministerial Conference on Youth Employment; 'How to improve, through skills development and job creation, access of Africa's youth to the world of work'. Abidjan, Côte D'Ivoire, 21-23 July 2014.

Republic of Kenya (2011). Kenya National Manpower Survey Report, 2010/2011. Nairobi. Kenya National Bureau of Statistics/Ministry of Labour, Social Security and Services

Robertson, S. (2016) Piketty, capital and education: a solution to, or problem in, rising social inequalities? British Journal of Sociology of Education. 37 (6), 823-835.

Romer, P. M. (1990) Endogenous Technological Change. Journal of Political Economy, 98, S71S102.

Teal, F. (2000) Employment and Unemployment in Sub-Saharan Africa: An Overview. Available at: http://www.csae.ox.ac.uk/conferences/2000-OiA/pdfpapers/teal.PDF

USAID/MEDA/FHI360. (2014). Workforce Connections: Kenya Youth Assessment. Nairobi. 
Van der Berg, S, and van Broekhuizen, H (2012) Graduate Unemployment in South Africa: A Much Exaggerated Problem. Stellenbosch University Economic Working Paper, 22/12.

Wangenge-Ouma, G. (2007) Higher education marketisation and its discontents: the case of quality in Kenya. Higher Education, 56 (4): 457-471.

Wilton, N. (2012) The impact of work placements on skills development and labour market outcomes for business and management graduates. Studies in Higher Education, 37 (5), 603-620.

World Bank (2013) Achieving Shared Prosperity in Kenya. Washington, DC: World Bank. 